\title{
Perancangan Alat Ukur Tegangan Permukaan dengan Induksi Elektromagnetik
}

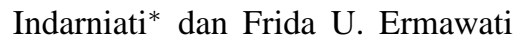 \\ Jurusan Fisika, Universitas Negeri Surabaya, \\ Jl. Ketintang, Surabaya 60231
}

Intisari

\begin{abstract}
Tegangan permukaan merupakan sifat permukaan suatu zat cair akibat pengaruh tegangan. Guna mengetahui seberapa besar nilainya dilakukan pengukuran dengan menggunakan susunan alat hasil rancangan yang menggunakan sensor induksi elektromagnetik, menggantikan Newtonmeter yang selama ini dipergunakan. Perancangan tersebut dimaksudkan untuk mengetahui apakah sensor induksi elektromagnetik dapat dipergunakan sebagai pengganti Newtonmeter dalam pengukuran tegangan permukaan zat cair, dan dapat menunjukkan proses fisika yang terjadi selama pengukuran tegangan permukaan berlangsung karena mengetahui perubahan tiap gaya tarik yang terjadi selama pengukuran, nilai gaya tarik tersebut, serta nilai tegangan permukaan zat cair dapat diketahui secara langsung. Hal ini dimungkinkan karena data ditampilkan dalam bentuk grafik. Penelitian mencakup persiapan, perencanaan, dan perakitan alat sampai dengan pengujian (studi kelayakan) hasil rancangan dengan menggunakan oli SAE 20W-50, oli SAE 30, dan bensin sebagai sampel uji.
\end{abstract}

KATA KUNCI: tegangan permukaan, induksi elektromagnetik, sensor induksi, Newtonmeter

\section{PENDAHULUAN}

Tegangan permukaan merupakan sifat permukaan suatu zat cair yang berperilaku layaknya selapis kulit tipis yang kenyal atau lentur akibat pengaruh tegangan. Pengaruh tegangan tersebut disebabkan oleh adanya gaya tarik-menarik antarmolekul di permukaan zat cair tersebut. Untuk mengetahui seberapa besar nilai tegangan permukaan suatu zat, maka cara sederhana yang dilakukan adalah dengan melakukan praktikum terhadap beberapa zat cair dengan menggunakan susunan alat seperti Gambar 1.

Newtonmeter difungsikan untuk mengukur nilai gaya tarik maksimum pada cincin saat pengambilan data, tanpa menunjukkan peristiwa fisis yang terjadi selama proses pengukuran

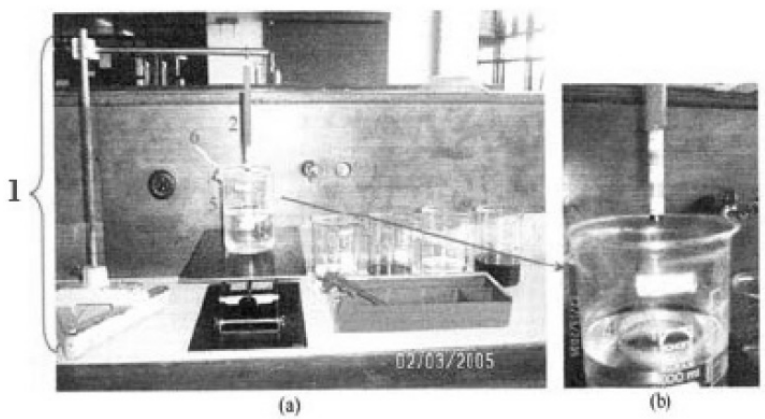

Gambar 1: (a). susunan alat ukur tegangan permukaan zat cair yang biasa digunakan untuk praktikum Fisika Dasar, (b) cincin aluminium yang digunakan dalam praktikum

${ }^{*}$ E-MAIL: indars@telkom. net tegangan permukaan berlangsung. Oleh karena itu peneliti berinisiatif untuk juga mengedepankan proses fisika yang terjadi selama pengukuran tegangan permukaan berlangsung. Inisiatif tersebut direalisasikan dengan memanfaatkan sensor induksi, yang bekerja berdasarkan prinsip induksi elektromagnetik, sebagai pengganti Newtometer pada Gambar 1 karena proses perubahan gaya tarik yang mengenai cincin terjadi selama pengukuran dapat direkam dan ditampilkan dalam bentuk grafik pada layar komputer.

susunan alat ukur tegangan permukaan yang mempergunakan sensor induksi tersebut diberikan pada Gambar 2 .

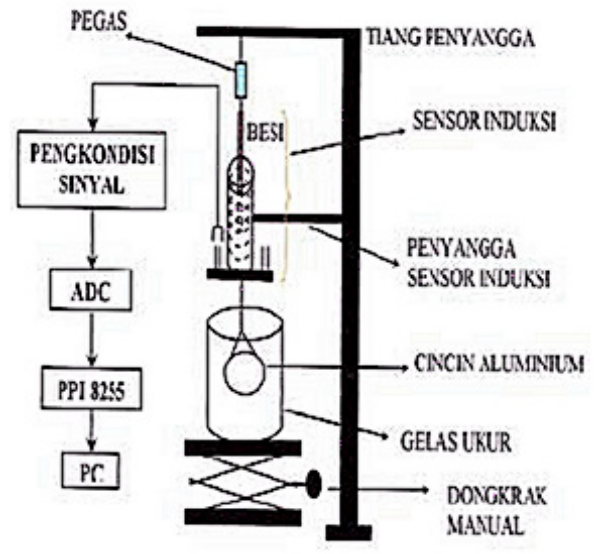

Gambar 2: Rancangan susunan alat ukur tegangan permukaan dengan memanfaatkan induksi elektromagnetik untuk sensor induksi 


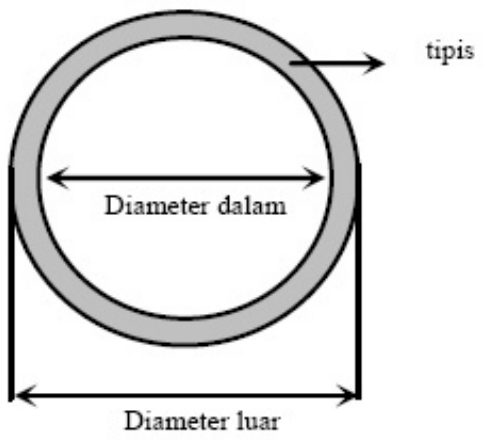

Gambar 3: Cincin Aluminium yang dipergunakan dalam penelitian (tampak atas)

\section{DASAR TEORI}

\section{A. TEGANGAN PERMUKAAN}

Besarnya tegangan permukaan merupakan usaha yang diperlukan cincin untuk menciptakan suatu permukaan baru, sifat permukaan yang dimiliki oleh zat cair yang berperilaku layaknya selapis kulit tipis yang kenyal atau lentur akibat pengaruh tegangan [1]. Tegangan ini terjadi jika molekulmolekul di permukaan suatu cairan saling tarik menarik satu sama lain, sehingga menciptakan pembatas antara udara dengan cairan itu. Dalam praktikum, tegangan permukaan $(\alpha)$ didefinisikan sebagai usaha yang diperlukan cincin untuk menciptakan suatu permukaan baru, dirumuskan sebagai [2]

$$
\alpha=\frac{W}{A}=\frac{F}{\ell}
$$

dengan $\mathrm{F}$ adalah gaya tarik (Newton), dan $\ell$ adalah panjang permukaan cairan yang menutupi cincin (meter). Cincin yang digunakan terbuat dari bahan aluminium, mempunyai dua permukaan luar dan dalam seperti Gambar 3, sehingga panjang permukaan yang terkena gaya permukaan menjadi $2 \ell=2 \pi \mathrm{d}$, dengan d adalah diameter cincin, sehingga Pers. 1 menjadi [2]

$$
\alpha=\frac{F}{2 \pi d}
$$

\section{B. INDUKSI ELEKTROMAGNETIK}

Induksi elektromagnetik yang dimanfaatkan untuk sensor induksi merupakan gejala terjadinya arus listrik dalam suatu penghantar akibat perubahan medan magnet pada penghantar tersebut. Prinsip kerja sensor ini adalah arus input (AC) dialirkan ke kumparan primer sensor. Timbulnya perubahan fluks pada besi diakibatkan oleh tegangan AC pada kumparan primer, sehingga besi bersifat magnet. Medan magnet dihasilkan, kemudian kumparan sekunder (output) di induksi. Terjadinya perubahan fluks tersebut akan menghasilkan GGL induksi atau arus induksi pada keluaran sensor [3-5]. Sensor

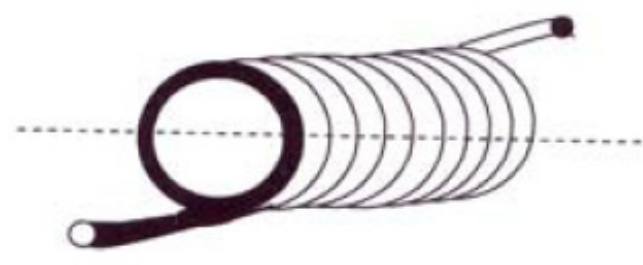

Gambar 4: Ilustrasi lilitan kawat tembaga (kumparan) yang dipergunakan sebagai sensor induksi berbentuk heliks

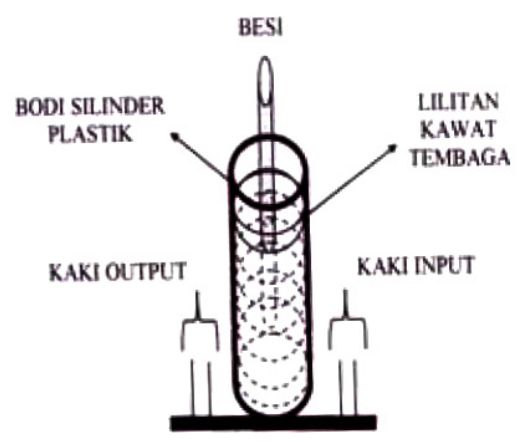

Gambar 5: Bagian-bagian sensor induksi (tampak samping)

akan menghasilkan gaya tarik yang menarik cincin, menyebabkan cincin bergerak tertarik ke atas. Saat itulah proses pengukuran gaya tarik dimulai. Pada penelitian ini kawat tembaga diameter $2 \mathrm{~mm}$ dipergunakan sebagai kumparan (Gambar 4).

Lilitan kawat tembaga dibuat sangat rapat dengan maksud agar diperoleh medan magnet yang homogen. Perbandingan antara jumlah lilitan kumparan primer dan sekunder adalah $\mathrm{N}_{p}: \mathrm{N}_{s}=1: 2$, lilitan primer sebagai input, sedangkan lilitan sekunder sebagai output. Kawat tembaga (kumparan) yang berfungsi sebagai penghantar pada sensor induksi dililitkan pada bodi silinder plastik berongga (tempat besi), seperti Gambar 5.

Besi digunakan untuk menghasilkan perubahan medan magnet akibat arus listrik yang mengalir pada kumparan. Adapun besi yang dipergunakan adalah besi pejal berbentuk silinder berwarna perak dengan diameter $(0,80 \pm 0,01)$ $\mathrm{cm}$, yang merupakan bahan ferromagnetik [6]. Dipilih bahan ini karena mampu menaikkan kuat medan magnetik yang dihasilkan oleh kumparan hingga ratusan bahkan ribuan kali lebih besar.

\section{ADC (ANALOG TO DIGITAL CONVERTER)}

ADC merupakan komponen pengubah data dari bentuk analog ke bentuk digital, yaitu alat yang mampu mengubah sinyal atau tegangan analog menjadi informasi digital yang nantinya akan diproses lebih lanjut dengan komputer. Dalam penelitian ini digunakan ADC0809 seperti pada Gambar 6 karena mudah dijumpai di pasar, harga terjangkau, dan memadai dalam penggunaannya.[7] 


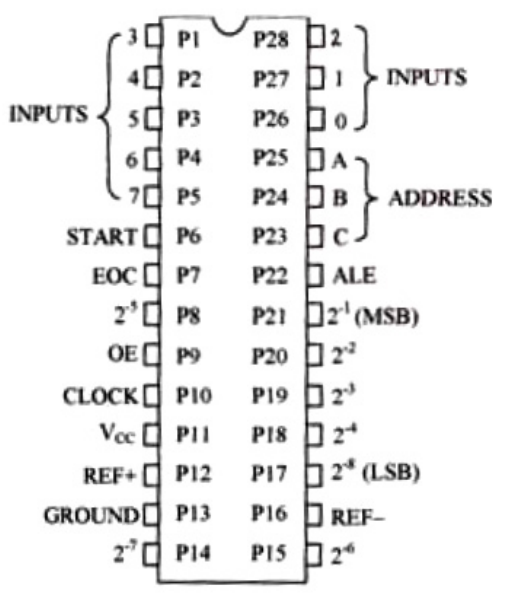

Gambar 6: Konfigurasi pin-pin pada IC ADC0809 (tampak atas)

\section{PPI 8255}

PPI (Programmable Peripheral Interface) adalah perangkat yang berfungsi untuk menjembatani antara mikroprosesor dengan komponen luar. Dalam hal ini mikroprosesor adalah perangkat dalam yang merupakan bagian dari PC, sedangkan yang dimaksudkan sebagai perangkat luar tersebut adalah semua komponen hardware yang bukan termasuk dalam sistem mikroprosesor itu sendiri. Fungsi utama kartu PPI 8255 adalah sebagai interface (antarmuka) komputer dengan peralatan dari luar komputer, yang dipasang pada slot komputer IBM. Komponen ini memiliki 25 pin, 24 pin digunakan untuk masukan atau keluaran, 1 pin sebagai $\mathrm{V}_{c c}$. [8]

\section{METODOLOGI PENELITIAN}

Pada penelitian ini ketiga zat cair tersebut masing-masing diketahui nilai gaya tariknya yang diukur secara manual, untuk oli SAE 20W-50 adalah $70 \mathrm{mN}$, oli SAE 30 adalah 68 $\mathrm{mN}$, dan bensin $60 \mathrm{mN}$. Dari data tersebut, alat hasil rancangan dikalibrasikan terhadap alat konvensional (manual seperti Gambar 1). Pada saat pengukuran berlangsung pada susunan alat hasil rancangan, data yang dibaca oleh PC adalah data dalam bentuk bit, dalam hal ini 8 bit (255 desimal). Kalibrasi yang dilakukan adalah dengan membandingkan nilai bit yang diterima oleh PC dari tiap-tiap zat cair dengan nilai tegangan permukaan yang diukur secara manual. Berdasarkan data yang diterima oleh PC dan diukur secara manual didapatkan data-data yang ditunjukkan Tabel I.

Perumusan yang digunakan (diset pada software) adalah :

$$
\begin{aligned}
\text { Tegangan permukan } & =\frac{\text { bit terbaca }- \text { bit minimum }(\mathrm{F}=0)}{\text { bit terbaca }- \text { bit minimum }} \\
& \times \text { gaya tarik maksimum }
\end{aligned}
$$

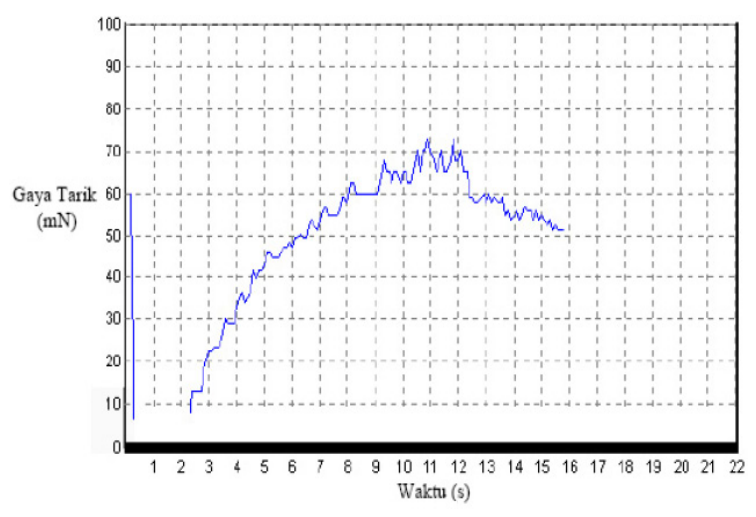

(a)Oli SAE 20W-50

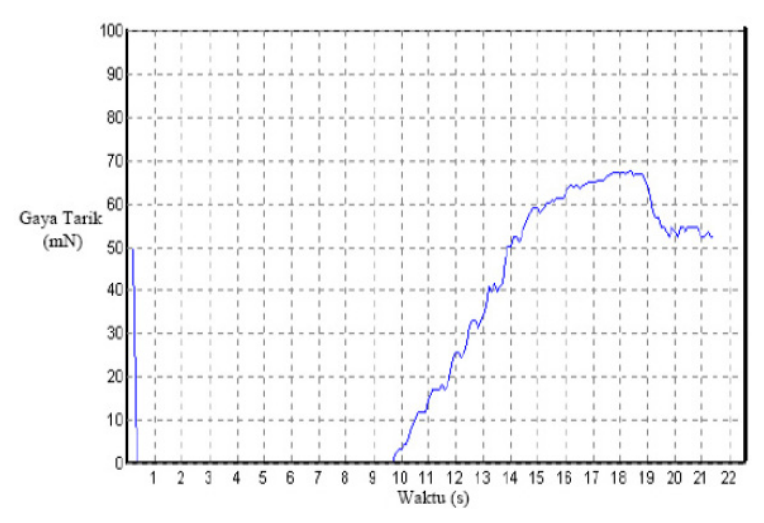

(b)Oli SAE 20W-30

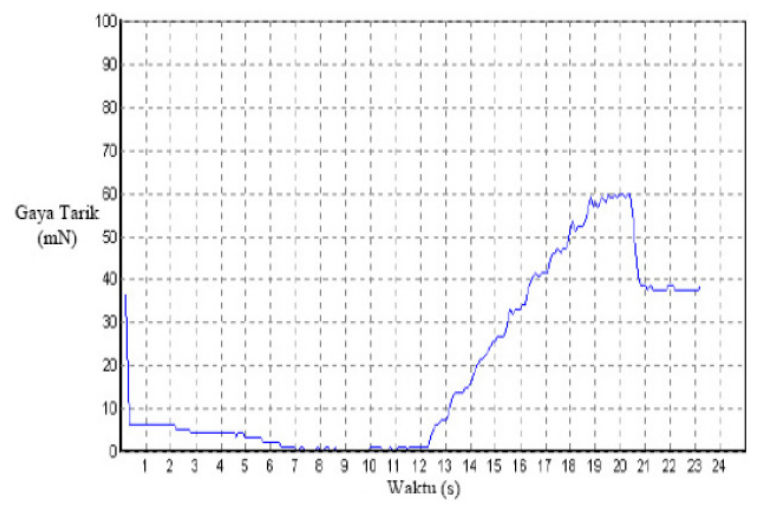

(c)Bensin

Gambar 7: Grafik tegangan permukaan

TABEL I: Nilai gaya tarik ketiga zat cair dengan bit yang terbaca oleh PC

\begin{tabular}{lcccc}
\hline \hline Zat cair & \multicolumn{2}{c}{$\begin{array}{c}\text { Gaya tarik (mN) } \\
\text { Minimum }\end{array}$} & \multicolumn{2}{c}{$\begin{array}{c}\text { Bit yang terbaca } \\
\text { Minimum }\end{array}$} \\
\hline Maksimum
\end{tabular}


TABEL II: Tegangan permukaan tiga macam zat cair yang diukur pada suhu $16-21^{\circ} \mathrm{C}$ baik secara manual dan susunan alat Gambar 2

\begin{tabular}{lccccc}
\hline \hline Sampel & $\begin{array}{c}\text { Manual } \\
\mathrm{F}(\mathrm{mN}) *\end{array}$ & $\alpha(\mathrm{N} / \mathrm{m}) * *$ & $\begin{array}{c}\text { Penelitian } \\
\text { (mN) }\end{array}$ & $\alpha(\mathrm{N} / \mathrm{m})$ & $\begin{array}{c}\text { Simpangan } \\
(\%)\end{array}$ \\
\hline Oli SAE 20W-50 & 70,7 & 0,189 & 70,4 & 0,189 & 0 \\
Oli SAE 30 & 68,7 & 0,184 & 67 & 0,180 & 2,2 \\
Bensin & 60,6 & 0,163 & 60 & 0,162 & 0,6 \\
\hline \hline
\end{tabular}

* F Gaya tarik rata-rata dari 15 kali pengambilan data

** $\alpha$ tegangan permukaan dihitung menggunakan Pers.2

\section{HASIL DAN DISKUSI}

Dari penelitian ini diperoleh data harga tegangan permukaan $(\alpha)$ beserta grafiknya untuk ketiga zat cair, seperti tersaji pada Gambar 7. Masing-masing grafik menggambarkan aktivitas cincin ketika melakukan kerja/usaha terhadap permukaan zat cair yang semula dalam keadaan normal (tidak adanya $\mathrm{F}$ tarik, $\mathrm{F}=0$ ) akan mengalami gaya permukaan sampai akhirnya menegang karena gaya tarik maksimum sehingga cincin terlepas dari permukaan zat cair (pada cincin terbentuk permukaan baru).

Berdasarkan hasil yang diberikan pada Tabel 2, nilai tegangan permukaan dari kedua susunan alat relatif sama. Hal ini disebabkan karena harga gaya tarik $(\mathrm{F})$ pada pengukuran manual dijadikan tolok ukur (Tabel 1) untuk pengukuran penelitian ini. Pada susunan manual hanya memberikan nilai gaya tarik tanpa adanya perubahan gaya tarik tersebut yang dapat diamati secara nyata. Untuk susunan penelitian (Gambar 2) data ditampilkan dalam bentuk grafik yang menunjukkan perubahan gaya tarik tiap satuan waktu dari awal tidak adanya gaya tarik $(F=0)$ dimana pada cincin tidak bekerja gaya apapun, sampai gaya tarik maksimum (F maksimum) dapat diamati dengan jelas. Nilai tegangan permukaan dan gaya tarik tersaji secara digital pada layar komputer.

\section{SIMPULAN}

Berdasarkan hasil penelitian dapat disimpulkan bahwa dengan susunan alat tegangan permukaan dengan memanfaatkan sensor induksi seperti gambar 2 ternyata lebih memudahkan peneliti dalam memahami perubahan gaya tarik tiap satuan waktu dari awal tidak adanya gaya tarik $(\mathrm{F}=$ 0) dimana pada cincin tidak bekerja gaya apapun, sampai gaya tarik maksimum ( $\mathrm{F}$ maksimum) selama pengukuran tegangan permukaan. Selanjutnya, karena gaya tarik yang dipergunakan dalam penelitian ini adalah sama seperti harga gaya tarik secara manual, maka hasil pengukuran tegangan permukaan yang diperoleh adalah sama untuk keduanya. Dengan kata lain, pengukuran tegangan dengan susunan manual hanya memberikan nilai saja, sedangkan susunan alat hasil rancangan memberikan nilai tegangan permukaan, juga perubahan gaya tarik tiap waktu yang diperlihatkan dalam grafik.
[1] Sears, Zemanzky, Fisika untuk Universitas I, Mekanika Panas Bunyi,(Bina Cipta, Bandung, 1985).

[2] Tim, Petunjuk Praktikum Fisika Dasar, Mekanika Panas Bunyi Getaran (FMIPA ITS, Surabaya, 2005).

[3] Surya, Yohanes, Olimpiade Fisika dan Latihan Fisika Menghadapi Masa Depan, Sekolah Menengah Umum, Caturwulan Kedua, (Cipta Ilmu, Jakarta, 1996).

[4] Foster, Bob, Terpadu Teori, Contoh Soal dan Penyelesaiannya, dan Evaluasi Fisika, SMU Kelas 3A, Tengah Tahun Pertama (Erlangga, Bandung, 1999).

[5] Foster, Bob, Terpadu Teori, Contoh Soal dan Penyelesaiannya, dan Evaluasi Fisika, SMU Kelas 3B, Tengah Tahun Kedua, (Erlangga, Bandung, 1990).
[6] Illingwort, Valerie, The Pinguin Dictionary of Physics, Edited by Valerie Illingworth, $2^{\text {nd }}$ ed., (Market House Books LTD, 1990).

[7] Eko Putra, Agfianto, Teknik Antarmuka Komputer, Konsep dan Aplikasi (Graha Ilmu, Yogyakarta, 1997)

[8] Sumaryadi, Slamet, Implementasi Interface PPI 8255 untuk Simulasi Pengaturan Informasi Kebakaran dengan Suara dan Membuka Valve Dilengkapi Sambungan Telepon, FTI, ITS (1997)

[9] Halliday - Resnick (Pantur Silaban - Erwin Sucipto), Fisika Jilid 2, Edisi Ketiga (Erlangga, Jakarta, 1999).

[10] Tim, Terampil Menerapkan Konsep dan Prinsip Fisika, 2A untuk Kelas 2 SMU, Cawu I dan Tengah Cawu II, (Tiga Serangkai, Surakarta, 1995). 